\title{
Ethanol in low chronic dose level attenuates major organic effects in malnourished rats
}

\author{
ALINE S DE AGUIAR ${ }^{1,2}$; GILSON T BOAVENTURA ${ }^{3}$; RAFAEL F ABRAHÃO ${ }^{1}$; \\ THATIANA L FREITAS ${ }^{1}$, CHRISTINA M TAKIYA ${ }^{4}$, PORPHIRIO J S FILHO ${ }^{5}$; \\ VILMA A DA SILVA ${ }^{1}$
}

\author{
${ }^{1}$ Núcleo de Ciências Comportamentais e do Desenvolvimento, Departamento de Fisiologia e Farmacologia, \\ Instituto Biomédico, Universidade Federal Fluminense \\ 2 Doutoranda em Patologia Investigativa, Pós Graduação em Patologia, Universidade Federal Fluminense/ \\ Hospital Universitário Antônio Pedro \\ ${ }^{3}$ Laboratório de Nutrição Experimental, Departamento de Nutrição e Dietética, Universidade Federal \\ Fluminense. \\ ${ }^{4}$ Departamento de Anatomia e Histologia. Universidade Federal do Rio de Janeiro \\ ${ }^{5}$ Departamento de Patologia. Universidade Federal Fluminense/ Hospital Universitário Antônio Pedro.
}

\begin{abstract}
The aim of the present study was to evaluate the chronic toxicity of ethanol low blood levels in malnourished rats. Female Wistar rats $(220 \mathrm{~g})$ were subjected to either an ad libitum diet (W, well-nourished, $\mathrm{n}=10)$ or food restriction ( $\mathrm{M}$, malnourished, $\mathrm{n}=10$ ). Water (WW and $\mathrm{MW}$ ) or ethanol solution (W5\% and M5\%) was offered to half of each nutritional group $(n=5)$ as the only fluid source. The treatment was continued for two months. After sacrifice, blood biochemical parameters and macroscopic, histologic and morphometric evaluation of the liver were performed. Results indicated that: Ethanol consumption was higher in malnourished rats and minimized body weight loss in malnourished rats, while it decreased the body weight gain in well-nourished ones. Behavioral ethanol intoxication was more severe in malnourished rats. Malnutrition decreased hematocrit and hemoglobin but, on the other hand, ethanol was a protective factor of that effect (hemoglobin: MW $10.6 \mathrm{mg} / \mathrm{dl} / \mathrm{ME} 13.02 \mathrm{mg} / \mathrm{dl}, \mathrm{p}<0.05)$. Ethanol increased the relative liver weight of both wellnourished and malnourished rats. Ethanol intake minimized iron pigment, collagen area and binuclear hepatocyte/ field increased by malnutrition. These data are in accordance with previous reports which showed ethanol as an important source of calories and, even chronically, ethanol still attenuates the effects of malnutrition.
\end{abstract}

Key terms: ethanol, low dose, malnutrition, toxicity

\section{INTRODUCTION}

Alcoholism may be considered as a chronic illness with a multifactorial etiology combining several components, genetic as well as organic, psychological and environmental (Addolorato et al., 2005).

As ethanol may be a source of calories to malnourished organisms and because of its anxiolytic action (Almeida et al., 1996), which may alleviate the stress and discomfort brought from hunger, it is possible to consider malnutrition as a risk factor for alcoholism. In fact, malnourished rats do drink more ethanol than wellnourished rats (Stiglick \& Woodworth, 1984).

Nonetheless, previous studies carried out by our group have shown that low doses of ethanol $(5 \% \mathrm{v} / \mathrm{v}$, ad libitum as the only available fluid source) had challenging effects on malnourished rats. Instead of increasing toxicity, rats kept under restricted food presented beneficial effects such as less mortality and better offspring psychomotor performance. (Da-Silva et al., 2000). 
Increased body weight in malnourished rats was detected after 90 days of exposure to ethanol at 20\% v/v (Da-Silva et al., 1982).

Aguiar et al (2004) evaluated the threshold dose in which ethanol would be useful as an energy source to malnourished rats. Ethanol solutions at 5, 10 and $20 \% \mathrm{v} / \mathrm{v}$ decreased body weight loss in malnourished rats and did not change biochemical parameters (hematocrit, hemoglobin, total protein and albumin). On the other hand, $a d$ libitum rats presented body weight loss when solution was $10 \% \mathrm{v} / \mathrm{v}$, with worse effects at $40 \% \mathrm{v} / \mathrm{v}$. However, the malnourished rats that benefited from ethanol calories showed more behavioral intoxication than the well-nourished ones (Aguiar et al., 2006). One limitation was that the ethanol treatment lasted only 7 days. Thus, the effects of chronic exposure were not investigated. Besides, increased body weight is not a guarantee of absence or decrement of drug toxicity.

The pathologic consequences of acute and chronic alcohol abuse are multifactorial and multisystemic (Molina et al., 2003). Ethanol toxicity has been extensively studied but most research has been performed with high doses of the drug. For instance, chronic consumption of high ethanol concentrations $(11-12 \mathrm{~g} / \mathrm{Kg})$ has negative effects in the liver and impairs the function of a wide range of cells and tissues (Iumuro et al., 1997). The few studies with lower dose levels indicate that ethanol may induce morphological and functional changes in hepatocytes (Puzziferri et al., 2000). As far as we know, the effects of malnutrition when ethanol exposure occurs in low dose levels and chronically have not been investigated. Studies designed to evaluate toxicity in target organs under the effect of low doses of ethanol, especially in long term exposure, are necessary. This represents a research area of great medical interest, mainly considering that most cultures approve moderate alcohol consumption and scientific evidence seems to support it (Dufour, 1999).

The food restriction model is closer to what occurs to millions of people exposed to poverty. About $8 \%$ of the adult Brazilian population is malnourished, which is thought to happen due to poverty resulting from under-employment and low wages (FAO, 2006). This situation could be favorable to alcohol intake and consequently to alcohol addiction.

Our hypothesis is that ethanol, in spite of being a caloric source to malnourished rats, will still be toxic to target organs and that this toxicity could be modified by malnutrition. The aim of the present study was to evaluate the toxicity of chronic exposure (two months) to low doses of ethanol $(5 \% \mathrm{v} / \mathrm{v})$ in two different nutritional states (food ad libitum and restricted to $50 \%)$.

\section{MATERIAL AND METHODS}

\subsection{Animals and treatment}

All animal work was carried out in accordance with the Brazilian Animal Protection Law and was approved by the Local Ethics Committee for Research at Hospital Universitário Antônio Pedro, Universidade Federal Fluminense, Brazil (n 172/05).

Twenty female Wistar rats (Rattus novergicus) weighing between 200-220g were placed in individual polyethylene cages $(41 \mathrm{x} 34 \mathrm{x} 16 \mathrm{~cm})$ and randomly assigned to groups of either water or ethanol, which were divided in two nutritional groups, thus generating four experimental groups. All the procedures were performed between 10:00 and 11:00 a.m. Groups were treated as described below:

- Well-nourished Water (WW) $(n=5)$ : receiving food (a commercial diet Nuvital Purina ${ }^{\circledR}$ Brazil) and water $a d$ libitum;

- Malnourished Water (MW) $(n=5)$ food restricted to $50 \%$ of consumption of WW and water ad libitum;

- Well-nourished ethanol 5\% v/v (W5\%) $(\mathrm{n}=5)$ : receiving food ad libitum and ethanol solution at $5 \% \mathrm{v} / \mathrm{v}$ as the only drinking source;

- Malnourished ethanol 5\% v/v (M5\%) $(n=5)$ : food restricted to $50 \%$ and ethanol solution at $5 \% \mathrm{v} / \mathrm{v}$ as the only drinking source. 
The treatment lasted two months, which is equivalent to 10 years of a human being's lifetime.

During the first three weeks of the experiment, all groups received water as liquid source, and the MW and M5\% ones were submitted to food restriction of $50 \%$ of the ad libitum consumption until they reached a weight loss of $20 \%$ (Stiglick \& Woodworth, 1984). Only after this criterion had been achieved did ethanol treatment begin.

\subsection{Intoxication test}

Rats were evaluated weekly through a modified behavioural intoxication scale proposed by Majchrowicz (1975). Before being weighed weekly, rats were observed in individual cages for 30 seconds and received the corresponding grade: 0: neutrality; 1: hypoactive, mildly ataxic; 2 : ataxic, elevated abdomen; 3: ataxic, non elevated abdomen; 4: loss of righting reflex, retain eye blink reflex; 5: loss of righting reflex, loss of eye blink reflex.

\subsection{Biochemical analyses}

Blood was collected by intracardiac puncture, under ether anaesthesia (Brzóska et al., 2003; Aguiar et al., 2006). Laboratory analysis of total proteins, albumin, hematocrit and hemoglobin were conducted using standard protocols, according to the manufacturers' instructions (Kits BIOCLIN â , QUIMASA QUÍMICA BÁSICA, MG, Brazil).

\subsection{Procedures for histopathological and histomorfometrical analyses}

Rats were killed by cervical dislocation. The liver was quickly removed, cleaned in cold saline, dried with filter paper and weighed. Then, a portion was dipped in Gendre's fixative for 6 hours and then maintained in $10 \%$ phosphate buffered formalin, dehydrated and embedded in paraffin. Sections of $5 \mu \mathrm{m}$ were prepared and stained with hematoxylin and eosin (H\&E) for histopathological routine, Periodic Acid- Schiff (PAS) for hepatocyte area (Kiernan, 1990), Picrosirius Red (PS) for collagen (Junqueira et al., 1979) and Perls and Stein techniques were performed in order to detect iron pigments and bilirrubin pigments, respectively (Kiernan, 1990). All sections were analysed by light microscopy (Leitz DFV) under the supervision of a pathologist (PJSF).

Histomorphometry was performed using an image analysis system composed of a digital camera (Evolution MP Color Media Cybernetics) coupled to a light microscope (Nikon Eclipse E400). Five fields of liver parenchyma (10x objective lens), considering avoiding liver capsule, portal spaces or central veins/ animal, were captured for hepatocyte binuclearity assessment. Ten fields of liver parenchyma from the perivenular (Zone III) and periportal (Zone I) region/ animal were also captured by a 40x objective lens. PAS stained slides were used to capture images for hepatocyte parameters quantification and PS for collagen. Quantification was estimated on captured high quality images (2048 x 1536 pixels buffer) by considering the total field area using the software ImagePro® Plus 4.5.1 (Media Cybernetics, USA).

\subsection{Ethanol blood determination}

An independent group of rats kept in the same experimental conditions was used for ethanol blood level measurement. These rats were exposed to one week of continuous $5 \% \mathrm{v} / \mathrm{v}$ ethanol. Blood was collected from the tip of the tail. Ethanol blood was measured using a head space technique (Da-Silva \& McLean, 1988). Briefly, $10 \mu \mathrm{L}$ of blood was placed in a 1.9 $\mathrm{mL}$ vial together with $10 \mu \mathrm{L}$ of the internal standard (100 mg\% propanol) and the vial was sealed. After 60 min of equilibration in a water bath at $38 \pm 1{ }^{\circ} \mathrm{C}, 500 \mu \mathrm{l}$ of the air present in each vial was injected into a gaschromatograph (Hewlett-Packard 573 A) connected to a C-R 1B Shimadzu integrator. The ratios of the peak areas derived from ethanol and the internal standard were compared with a standard curve of ethanol solutions at 40, 20, 10, 5 and $2.5 \mathrm{mg} \%$ (prepared with ethanol absolute PA Merck® + saline). 


\subsection{Statistical analysis}

Experimental groups were compared by non-parametric tests (U- Mann Whitney) and whenever data fulfilled criteria for parametric statistics, the test was performed by using SPSS for Windows 12.0. Analyses of variance (ANOVA) of one factor (oneway), followed by the Student's t test, were used to compare body weight data. The two-way ANOVA was used to compare the effects of two independent factors: the nutritional state (well-nourished or malnourished) and the treatment (water and ethanol). Intoxication and biochemical parameters were analyzed with the U Mann Whitney Test (WW x MW and W5\% $\mathrm{x} \mathrm{M} 5 \%)$. Data were presented as mean \pm standard deviation (SD) or median (maximus and minimal values), and $\mathrm{p}$ values below 0.05 (two tailed) were considered significant.

\section{RESULTS}

\subsection{Ethanol intake, water intake and ethanol blood levels}

Ethanol consumption in $\mathrm{g} / \mathrm{kg}$ body weight was higher (approximately twice) in the malnourished group throughout the experiment. (Means in $\mathrm{g} / \mathrm{kg}$ for each week: W5\% 6.3; 8.6; 7.9; 7.0; 5.8; 6.5; 6.3; 6.2/ M5\%:11.3; 16.4; 22.1; 17.5; 16.3; 14.5; $15.1 ; 14.1 \mathrm{~g}, \mathrm{p}<0.05$ U- Mann- Whitney Test for all weeks W5\% x M5\%). In spite of this increased consumption, there were no statistically significant differences between groups concerning ethanol blood levels (mean: $1.43 \mathrm{mg} \% \pm 1.86$ ).

There were no statistically significant differences on daily water intake between WW and MW groups throughout the experiment. Means for the last week of experiment were as following: WW: $32 \pm$ 1,92 $\mathrm{mL}$ and MW: 23,3 $\pm 1,15 \mathrm{~mL}$.

\subsection{Body weight}

Ethanol had opposite effects according to the nutritional state. Malnourished rats treated with ethanol had the severe effects of malnutrition minimized and increased survival. Two malnourished rats which were not exposed to ethanol died before the end of the experiment. At the time, their body weight was around $120 \mathrm{~g}$. On the other hand, rats kept with food ad libitum decrease the body weight gain significantly when exposed to ethanol at $5 \%(\mathrm{p}<0.05)$ (Figure 1$)$.

\subsection{Intoxication}

Significant differences related to intoxication grades between groups were detected only on the second week. (Intoxication grade: W5\%: 0 x M5\% $2.0 \mathrm{p}<$ 0.05 Mann Whitney U test).

\subsection{Biochemical analyses}

The chronic ethanol intake $(5 \% \mathrm{v} / \mathrm{v})$ did not change the biochemical parameters of the well-nourished rats. Malnutrition decreased hematocrit and hemoglobin levels (Hematocrit: WW: 36\% x MW: 31\%/ Hemoglobin WW: $13.5 \mathrm{~g} / \mathrm{dl}$ x MW: $10.6 \mathrm{~g} /$ $\mathrm{dl} p<0.05$ Mann Whitney U test). However, ethanol consumption at $5 \% \mathrm{v} / \mathrm{v}$ attenuated the effects of malnutrition (Hematocrit: M5\% 37.2\% and hemoglobin M5\%: $13.2 \mathrm{~g} /$ dl). No significant differences between groups were found in total protein and albumin (Table I).

\subsection{Liver and histopathology}

Malnutrition decreased liver weight (g/100g body weight). Ethanol increased this parameter in both groups. The two-way ANOVA revealed significant effects of nutrition and ethanol, without significant interaction between factors. WW: $2.99 \pm$ $0.25 \mathrm{~W} 5 \%: 3.38 \pm 0.30 \mathrm{MW} 2.61 \pm 0.10$ $\mathrm{M} 5 \% 3.02 \pm 0.17(\mathrm{p}<0.05$ for nutritional state F: 10.4 and ethanol intake F: 12.06 ANOVA two-way).

Histological examination of the liver was normal in all well-nourished rats (WW and $\mathrm{W} 5 \%)$. There were no significant effects of ethanol in liver histology. Briefly, the expected inflammatory portal infiltrate was observed in all animals (WW, W5\%, MW and M5\%), the trabecular structure of the lobules was preserved and bilirrubin 


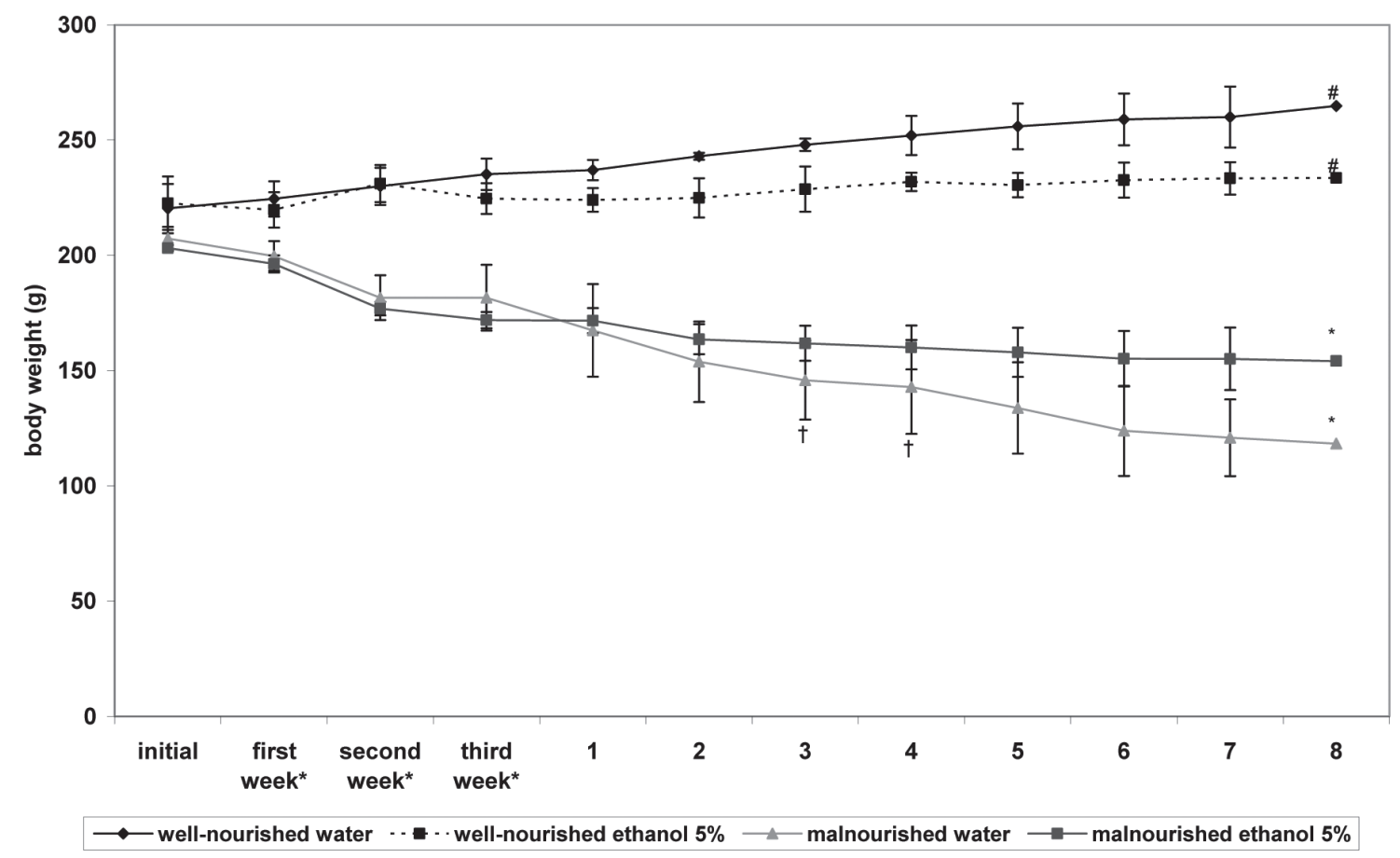

Figure 1: Body weight (g) of well-nourished and malnourished rats drinking either ethanol at 5\% v/ $\mathrm{v}$ or water for eight weeks

* First to third week: water for all groups until malnourished rats reached a weight loss of $20 \%$.

$\dagger$ Two rats died in group MW.

$\# * \mathrm{p}<0.05$ (ANOVA one-way followed by Student's $\mathrm{t}$ test)

TABLE I

Hematocrit, hemoglobin, total protein and albumin values of the well-nourished and malnourished rats exposed to water or ethanol at $5 \% \mathrm{v} / \mathrm{v}$ for eight weeks

\begin{tabular}{lcccc}
\hline & Hematocrit $(\%)$ & Hemoglobin $(\mathrm{g} / \mathrm{dL})$ & Total Protein $(\mathrm{g} / \mathrm{dL})$ & Albumin $(\mathrm{g} / \mathrm{dL})$ \\
\hline Well-nourished & & & & \\
Water (WW) & $36.6^{\mathrm{a}}(34-39)$ & $13.5^{\mathrm{b}}(12.5-14.5)$ & $6.9(6.7-7.4)$ & $4.2(3.9-4.8)$ \\
Ethanol (W5\%) & $38.2(37-40)$ & $13.4(12.5-14.5)$ & $7.5(7.0-7.9)$ & $4.6(4.2-5.0)$ \\
Malnourished & $31^{\mathrm{a}}(28-34)$ & $10.6^{\mathrm{b}} \mathrm{c}(10-11.5)$ & $6.6(5.9-7.3)$ & $4.0(4.0-4.1)$ \\
Water (MW) & $37.2(33-40)$ & $13.0^{\mathrm{c}}(12.3-13.5)$ & $6.7(6.2-7.2)$ & $4.1(3.8-4.6)$ \\
\hline
\end{tabular}

a,b,c Values are significantly different ( $\mathrm{p}<0.05 \mathrm{U}$-Mann Whitney) according to paired superscripts Median (minimal - maximus values)

WW (n=5) / WE5\% (n=5)/ MW (n=3)/ M5\% (n=5) 
pigment was not observed. In malnourished rats $(\mathrm{MW})$, important cell atrophy and iron pigmentation were observed, but the iron pigmentation was minimized by ethanol intake (M5\%). The hepatocyte area quantification was sensible to detect the cell atrophy observed in malnourished rats (MW), thus certifying that the method was sensible to detect that chronic ethanol intake did not change the cell area (Table II). The cell atrophy observed in malnourished rats (MW) was confirmed by the increased number of the hepatocyte cell/ field $(\mathrm{F}=12.28 \mathrm{p}=0.004$ two-way ANOVA) (Table III). Ethanol intake interacted with malnutrition only when the number of binuclear hepatocytes was analysed. ( F = $11.02 \mathrm{p}=0.006$ two-way ANOVA).

Malnutrition (MW) increased the collagen content in both regions. Ethanol intake minimized this effect only in the perivenous region (Table IV).

TABLE II

Hepatocytes area $\left(\mu \mathrm{m}^{2}\right)$ in perivenous and periportal regions of well-nourished and malnourished rats exposed to water or ethanol at $5 \% \mathrm{v} / \mathrm{v}$ for eight weeks

\begin{tabular}{lcc}
\hline & Perivenous $^{\mathrm{a}}$ & Periportal $^{\mathrm{b}}$ \\
\hline Well-nourished & & \\
Water $(\mathrm{WW})(\mathrm{n}=5)$ & $203.80 \pm 64.87$ & $232.50 \pm 77.47$ \\
Ethanol (W5\%) $(\mathrm{n}=5)$ & $227.80 \pm 69.96$ & $236.63 \pm 82.42$ \\
Malnourished & & \\
Water $(\mathrm{MW})(\mathrm{n}=3)$ & $123.15 \pm 38.86$ & $160.28 \pm 53.01$ \\
Ethanol $(\mathrm{M} 5 \%)(\mathrm{n}=5)$ & $127.21 \pm 47.13$ & $118.58 \pm 47.12$ \\
\hline
\end{tabular}

${ }^{\mathrm{a} b} \mathrm{p}<0.05$ for nutritional state $\left({ }^{\mathrm{a}} \mathrm{F}=62.46 /{ }^{\mathrm{b}} \mathrm{F}=155.83-\right.$ Two-way ANOVA $)$

Mean \pm SD

Image pro-Plus 4.0 (PAS 400x) Program was used.

TABLE III

Number of hepatocyte cells and binuclear hepatocytes in each histological field evaluated by optical microscopy of the liver of well-nourished and malnourished rats exposed to water or ethanol at $5 \% \mathrm{v} / \mathrm{v}$ for eight weeks

\begin{tabular}{lcc}
\hline & BinuclearHepatocyte acd & Hepatocyte cell/ field $* \mathbf{b}$ \\
\hline Well-nourished & $16.92 \pm 4.49$ & $295.40 \pm 21.80$ \\
Water (WW) & $16.96 \pm 3.63$ & $299.60 \pm 38.78$ \\
Ethanol (W5\%) & & $378.0 \pm 107.76$ \\
Malnourished & $37.26 \pm 3.30$ & $358.4 \pm 55.86$ \\
Water (MW) & $20.80 \mathrm{n} \pm 6.18$ & \\
Ethanol (M5\%)
\end{tabular}

* Field area: $0.175 \mathrm{~mm}^{2}(\mathrm{H} \& \mathrm{E} 100 \mathrm{x})$

Mean \pm SD

${ }^{\mathrm{a} b} \mathrm{p}<0.05$ for nutritional state $\left({ }^{\mathrm{a}} \mathrm{F}=22.08 /{ }^{\mathrm{b}} \mathrm{F}=12.28\right.$ Two-way ANOVA)

${ }^{\mathrm{c}} \mathrm{p}<0.05$ for ethanol intake $(\mathrm{F}=10.92$ Two-way ANOVA)

$\mathrm{d} p<0,05$ for interaction nutritional state $\mathrm{x}$ ethanol intake $(\mathrm{F}=11,02$ Two-way ANOVA) 


\section{TABLE IV}

Collagen area $\left(\mu \mathrm{m}^{2}\right)$ of perivenular and periportal regions of well-nourished and malnourished rats exposed to water or ethanol at $5 \% \mathrm{v} / \mathrm{v}$ for eight weeks

\begin{tabular}{lcc}
\hline & Perivenous $^{\text {ac }}$ & Periportal $^{\mathbf{b}}$ \\
\hline Well-nourished & & \\
Water (WW) & $494.12 \pm 289.63$ & $703.99 \pm 528.19$ \\
Ethanol (W5\%) & $492.11 \pm 303.15$ & $560.16 \pm 442.96$ \\
Malnourished & & \\
Water (MW) & $1531.72 \pm 904.74$ & $1435.76 \pm 1370.93$ \\
Ethanol (M5\%) & $1006.52 \pm 529.13$ & $1010.23 \pm 690.56$ \\
\hline
\end{tabular}

Mean \pm SD

${ }^{\mathrm{a} b} \mathrm{p}<0,05$ for nutritional state $\left({ }^{\mathrm{a}} \mathrm{F}=29.16 /{ }^{\mathrm{b}} \mathrm{F}=10.27\right.$ - Two-way ANOVA)

${ }^{c} \mathrm{p}<0,05$ for ethanol intake $(\mathrm{F}=5.03$ - Two-way ANOVA)

WW ( $=5) /$ W5\% ( $=5) /$ MW (n=3)/ M5\% ( $=5)$

Image pro-Plus 4.0 Program was used.

\section{DISCUSSION}

Data of the present study are indicative that ethanol in low doses can be toxic but still attenuates the effects of malnutrition. This assumption was derived from the exposure to low levels of ethanol chronically. Thus, well-nourished rats exposed to ethanol presented a decrease in body weight gain and increase in relative liver weight without important toxic effects on liver morphology or blood biochemistry. This could be suggestive of the known malnourishing effect of ethanol, which, in this case, was mild. In spite of being a malnourishing drug, ethanol decreased the severe effects of food restriction. Ethanol at $5 \% \mathrm{v} / \mathrm{v}$ in drinking solution was beneficial to malnourished rats in all parameters evaluated in this study (body weight, biochemical parameters and liver histopathology). This is in accordance with Aguiar et al (2004), who reported that malnourished rats utilized ethanol calories for body weight maintenance up to ethanol concentrations in drinking water at $20 \% \mathrm{v} / \mathrm{v}$.

Malnutrition significantly increased ethanol consumption in $\mathrm{g} / \mathrm{kg}$ body weight. This finding is in agreement with the study reported by Stiglick \& Woodworth (1984), in which food restricted rats displayed higher ethanol consumption. The higher intake of ethanol resulted in eventual higher degrees of intoxication (only on the second week of the experiment). Water intake was not different between malnourished and control rats. Therefore, increased ethanol intake cannot be considered as non-specific increased fluid intake. Different mechanisms might be envolved in this increased ethanol intake, which has also been observed by other authors (McGregor et al, 1999). Previous studies have demonstrated a close relationship between changes in body weight and voluntary ethanol intake (Aguiar et al, in press).

Differences in ethanol blood levels were not significant. As ethanol distributes in water, volume of distribution is decreased proportionally to fat content. This could explain why even drinking more, blood levels were the same in both nutritional conditions.

Food restriction resulting in malnutrition decreased relative liver weight. This could be because of the atrophy and hepatocyte hipoplasia (Parra et al, 1995). On the other hand, the association of ethanol in malnourished rats resulted in increase of liver weight of $15 \%$ (compared to group 
MW), while in well-nourished rats, the increase was of $13 \%$. Chronic consumption of ethanol alters $\mathrm{Na}^{+}$and $\mathrm{K}^{+}$channels, thus increasing intracellular water (Wondergem \& Davis, 1994, Häussinger \& Schliess, 1995) and cell size as well as promoting fat and proteins increase (Lieber, 2004). In the present study, the increase in relative liver weight was an important marker of ethanol toxicity even when light microscopy was unable to detect significant changes.

There has been little research directed to the study of toxicity of chronic exposure to ethanol in low doses. Puzziferri et al (2000) reported that chronic exposure at $3 \% \mathrm{v} / \mathrm{v}$ ethanol with blood levels of $4 \mathrm{mg} \%$ in Wistar rats resulted in a slight, although significant increase in lipidic mytochondrial peroxidation. This could be indicative of more extensive damage previously observed in rats exposed to high doses of that substance. A higher dose of ethanol, $(40 \% \mathrm{v} / \mathrm{v})$ results in steatosis, hepatitis, necrosis of hepatocytes and fibrosis, thus being suggested as an experimental model of the hepatic alcoholic disorder in Wistar rats (Keegan et al., 1995). Other authors who evaluated the toxicity of low doses of ethanol. Brzóska et al (2003) reported that Wistar rats exposed to $10 \% \mathrm{v} / \mathrm{v}$ ethanol for 12 weeks did not show any body weight changes. However, the authors reported important changes in hepatic trabecular structure and increased hepatocytes with cytoplasmatic vacuoles in zones I and III. Ito et al (2007) reported no changes in liver injury markers in Wistar rats drinking ethanol at $10 \% \mathrm{v} / \mathrm{v}$. Histological examination of the liver showed microvesicular steatosis.

The characteristic Liver Alcoholic Disorder (steatosis, hepatitis and fibrosisHarrison \& Burt, 1993), is not observed when ethanol concentrations are low. However, all the authors reported some changes in liver parameters that could be predictive of toxicity. In our study, the most sensitive parameter was the liver weight.

Our study also demonstrated that malnutrition induces several effects in liver histopathology especially in zone III. Ethanol did not reverse all these changes but minimized them. Apparently, the known effects of malnutrition (Parra et al., 1985) are attenuated by the caloric effect of the drug, which at this dose level would be more beneficial than its slight and, perhaps, initial toxicity. Of great importance was the observation that malnourished animals presented increased deposition of collagen in the perivenular region, which was attenuated by ethanol. The most commonly associated characteristic of fibrosis is an increased deposition of collagen (Gutiérrezruiz \& Gomez-Quiroz, 2007). One can dare to speculate that in malnourished animals ethanol would diminish the potential danger of induced fibrosis. In low dose levels, the toxic effects of the drug would not be as important as its caloric protection against the severity of malnutrition. Perhaps the concentration of $5 \%$ or blood levels of $1,4 \mathrm{mg} \%$ would be the threshold for this paradoxical effect. In humans, these blood levels are observed after the ingestion of 30 $\mathrm{mL}$ of beer, which is unlikely to occur in usual conditions. Therefore, we are speculating about protective effects in much lower levels than the low risk levels established by World Health Organization (around 2-3 bottles a day). However, if a protective effect is unlikely to occur, in human conditions, it is extremely important that even very low levels of ethanol might already be toxic. Mild and perhaps initial signs of toxicity were detected in liver morphology and brain function (intoxication).

Many people in developing countries drink ethanol and are already malnourished. Ethanol is not an ideal source of calories, but, unfortunately, can be the cheapest. If it is possible that its calories may diminish the deleterious effects of malnutrition, but certainly in very restricted dose levels and conditions. Nevertheless, it must be considered that chronic exposure to ethanol, even at low doses $(3 \% \mathrm{v} / \mathrm{v})$, may have important brain effects. Dopamine receptors, which are related to the complex events that result in drug dependence, have been described to change their density or affinity (Lograno et al., 1993). Whether ethanol can be attractive to the malnourished organism for its caloric value and it may indeed be protective at some 
blood levels, it is still relevant to consider that ethanol dependence will be more likely to occur. Malnutrition would be a risky factor for alcoholism because it favours the consumption of higher volumes of ethanol, which may lead to the development of ethanol dependence. Future research should address this hypothesis.

In summary, ethanol is a complex drug and its effects may vary depending on dose levels and nutritional state. It is not just a quantitative difference, but a qualitative one as well (toxic to the well-nourished, protective to the malnourished). However, because of the complexity of the dependence phenomenon and of the effects of ethanol in target organs, brain is still vulnerable to ethanol effects even at low doses. In our study, this could be seen in higher and intermittent grades of intoxication. Although and because it is attenuated by ethanol, malnutrition may be a risky factor for ethanol dependence.

\section{ACKNOWLEDGMENTS}

We are grateful to $\mathrm{Mr}$ Redinei. A. Laurindo, Mr Donaldo. S. Coutinho, Ms Solange. A. de Sá, Ms Lavínia Leal and Ms Ana Maria Martins for technical assistance, to Prof. Dr Vânia Silami for suggestions to manuscript, to Ms Maria Inês A. Alonso for reviewing the document and to $\mathrm{CNPq}$ for financial support.

\section{REFERENCES}

ADDOLORATO G, LEGGIO L, ABENAVOLI L, GASBARRINI G (2005) Neurobiochemical and clinical aspects of craving in alcohol addiction: a review. Addict Behav 30: 12091224

AGUIAR AS, DA-SILVA VA, BOAVENTURA GT (2004) Can calories from ethanol contribute to body weight preservation in malnourished rats? Braz J Med Biol Res 3: 841-846

AGUIAR AS, DA-SILVA VA, BOAVENTURA GT (2006) Behavioral toxicity of increasing doses of ethanol in malnourished rats. Nutr Neurosci 9: 113-119
AGUIAR AS, ABRAHÃO RF, FREITAS TV, DA-SILVA VA (2008) Early malnutrition favours heavy ethanol intake in weaning rats without long lasting effects. Nutr Neurosci (in press)

ALMEIDA SS, TONKISS J, GALLER JR (1996) Malnutrtion and reactivity to drugs acting in the Central Nervous System. Neurosci Behav Rev 20: 389-402

BRZÓSKA MM, MONIUSZKO-JAKONIUK J, PILATMARCINKIEWICZ B, SAWICKI B (2003) Liver and kidney function and histology in rats exposed to cadmium and ethanol. Alcohol Alcohol 38: 2-10

DA-SILVA VA, DA-SILVA JB, GISMONDI RAOC, REBELLO GP (2000) Ethanol improves lactation outcome in malnourished rats. Nutr Neurosci 3: 277-282

DA-SILVA VA, KOPELMAN BI, MACELLANO MTT, SMIGD JS, FREITAS CA (1982) Interação entre a desnutrição e o consumo de etanol antes e durante a gestação: efeitos sobre o desenvolvimento e comportamento da prole de ratos. J Pediatr 5: 306-313

DA-SILVA VA, MCLEAN, AEM (1988) Effect of two different types of malnutrition on the rate of elimination of ethanol in rats. Biochem Pharmacol 37: 4235-4238

DUFOUR MC (1999) What is moderate drinking? Alcohol Res Health 23: 5-14

FOOD AND AGRICULTURE ORGANIZATION OF THE UNITED NATIONS (FAO) (2006) The State of Food Insecurity in the World: eradicating world hunger - taking stock ten years after the World Food Summit < http: // www. fao.org/drocep/009/a0750e/a0750e00 > Acessed: 13 nov. 2007

GUTIÉRREZ-RUIZ MC, GÓMEZ-QUIROZ LE (2007) Liver fibrosis: searching for cell model answers. Liver 27: 434 439

HARRISON DJ, BURT AD (1993) Pathology of alcoholic liver disease. Baillière's Clin Gastroenterol 7: 641 -662

HÄUSSINGER D, SCHLIESS F (1995) Cell volume and hepatocellular function. J Hepatol 22: $94-100$

ITO DT, MOLINA HM, ANDRIOLO A, BORGES DR (2007) The combination of atorvastatin and ethanol is not more hepatotoxic to rats than the administration of each drug alone. Br J Med Biol Res 40: 343-348

IUMURO Y, FRANKENBERG MV, ARTEEL GE, BRADFORD BU, WALL CA, THURMAN RG (1997) Female rats exhibit greater susceptibility to early alcohol-induced liver injury than males. Am J Physiol 272: G 1186-G1194

JUNQUEIRA LCU, BIGNOLAS G, BRENTANI RR (1979) Picrosirius staining plus polarization microscopy, a specific method for collagen detection in tissue sections Histochem $\mathbf{J}$ 11: 447-455

KEEGAN A, MARTINI R, BATEY R (1995) Ethanol-related liver injury in the rati a model of steatosis, and pericentral fibrosis inflammation. J Hepatol 23: 591-600

KIERNAN JA (1990) Histological and histochemical methods. Theory and practice. Pergamon Oxford. Pp: 182-188

LIEBER CS (2004) Alcoholic fatty liver: its pathogenesis and mechanism of progression to inflammation and fibrosis. Alcohol 34: 9-19

LOGRANO DE, MATTEO F, TRABUCCHI M, GOVONI S, CAGIANO R, LACOMBA C, CUOMO V (1993) Effects of chronic ethanol intake at a low dose on the rat brain dopaminergic system. Alcohol. 10: 45-49

MAJCHROWICZ E (1975) Induction of physical dependence upon ethanol and the associated behavioral changes in rats. Psychopharmacology 43: 245-254

McGREGOR, JS, SAHAROV, T, HUNT, GE (1999). Beer consumption in rats: the influence of ethanol content, food deprivation, and cocaine. Alcohol, 17: 47-56

MOLINA PE, HOEK JB, NELSON S, GUIDOT DM, LANG CH, WANDS JR, CRAWFORD JM (2003) Mechanisms of Alcohol-Induced Tissue Injury. Alcohol Clin Exp Res 27: 563-575 
PARRA OM, HERNANDEZ-BLASQUEZ FJ, SILVA RAPS, SILVA JRMC, PEDUTO L, SOARES MM, SAAD WA, JUNIOR AS (1995) Reduction of liver mass due to malnutrition in rats: correlation with emaciation of animals and size of organs not inserted in the portal system. São Paulo Med J 113: 903-909

PUZZIFERRI I, SIGNORILE A, GUERRIERI F, PAPA F, CUOMO V, STEARDO L (2000) Chronic low dose ethanol intake: biochemical characterization of liver mitochondria in rats. Life Sci 66: 477-484

STIGLICK A, WOODWORTH I (1984) Increase in ethanol consumption in rats due to caloric deficit. Alcohol 1 : 413-415

WOLDERGEM R, DAVIS J, (1994) Ethanol increases hepatocyte water volume. Alcohol Clin Exp Res 18: $1230-1236$. 